\title{
Framingham Risk Score and clinical outcomes of forearm autologous arteriovenous fistulas in end- stage renal disease patients: a retrospective cohort study.
}

Jing Du

Shandong University

Qinlan Chen

Shandong University

Liming Liang

Shandong Qianfoshan Hospital

Xianglei Kong ( $\square$ kxl1985@163.com )

Shandong Qianfoshan Hospital https://orcid.org/0000-0002-6764-6522

Dongmei Xu

Shandong Qianfoshan Hospital

Research article

Keywords: Framingham risk score, autologous arteriovenous fistula, prognosis; cohort study

Posted Date: August 13th, 2019

DOI: https://doi.org/10.21203/rs.2.12771/v1

License: (1) This work is licensed under a Creative Commons Attribution 4.0 International License.

Read Full License 


\section{Abstract}

Background The failure of autologous arteriovenous fistulas (AVF) and cardiovascular disease (CVD) share several common risk factors. The Framingham risk score (FRS) can predict the occurrence of CVD. Accordingly, we conducted a retrospective cohort study to evaluate if the FRS can predict the AVF failure in end-stage renal disease (ESRD) patients. Methods In this study, 188 ESRD patients (with the mean age $57.2 \pm 13.8$ years, $64.9 \%$ of them were males) were enrolled with a median follow-up time of 41 months. AVF failure was defined as the presence of stenosis or thrombosis, and loss of the ability to receive prescribed hemodialysis. Primary patency of AVFs, and the association between FRS and AVF failure or death were analyzed by the Kaplan-Meier method or Cox proportional hazards model, accordingly. Results The primary patency of AVFs was $84.6 \%, 79.3 \%, 76.6 \%, 76.1 \%$ and $76.1 \%$ at $12,24,36,48$ and 60 months, respectively. However, there was no significant difference of the primary patencies among the 1 st Quartile, 2nd Quartile, 3rd Quartile and 4th Quartile of FRS (log-rank test, $p=0.15$ ). Moreover, FRS was not associated with all-cause or CVD mortality after adjusting for other confounders in the Cox proportional hazards models. Conclusions This study did not find FRS associated with AVF failure or mortality among ESRD patients.

\section{Background}

Chronic kidney disease (CKD) has become a major public health problem worldwide[ 1] and in China[ 2] over the past few decades, which can lead to end-stage renal disease (ESRD) in many people and also being risk factors for cardiovascular disease (CVD)[ 3]. More than 2 million people worldwide receiving hemodialysis therapy to treat ESRD[ 4]. In China, the prevalence of CKD was $10.8 \%$, and the number of patients with CKD was estimated to 119.5 million[ 2]. Furthermore, the incidence and prevalence of dialysis in China were 15.4 per million population (pmp)/year and 237.3 pmp in 2011, respectively[ 5]. Autologous arteriovenous fistula (AVF) is the preferred vascular access with lower mortality and lower infection rates used for chronic $\operatorname{HD}[6,7]$. In clinical practice, there is substantial international variation in the use of AVF, as successful AVF use was $84 \%$ in Japan[ 8], 76\% in Korea[ 9], 67\% in Europe and only 64\% in the United States[ 10]. Therefore, AVF failure is also a major issue of vascular access related to the HD. A recent study demonstrated that the primary and secondary patency of AVFs at one year were only $64 \%$ and $79 \%[11]$, which further confirms the importance of intensive examinations for the early detection of clarifying risk factors to prevent the occurrence of AVF failure. However, 
to date most of the studies about the risk factors for AVF failure were still controversial[ $12,13]$.

The Framingham risk score (FRS) has been well validated for cardiovascular risk stratification, and was revised in 2008 and became the Framingham general CVD risk score[ 14]. Now, FRS is the most commonly used algorithm in clinical practice to predict cardiovascular disease (CVD) risk. Recent studies demonstrated that the failure of AVF and CVD share several common risk factors, such as elderly, hypertension, diabetes and arterial stiffness[ 15-17]. However, the relationship between FRS and the AVF failure is still uncertain. Accordingly, we conducted a retrospective cohort study to evaluate if the FRS can correctly predict the AVF failure in ESRD patients.

\section{Method}

\section{Study population}

The study was a single-center retrospective cohort study, ESRD patients were enrolled between January 2013 and June 2016. The deadline of follow-up time was November $10^{\text {th }}, 2018$. AVFs were created at the cephalic vein to radial artery, of the left or right lower half of the forearm in CKD stage 4-5 patients evaluated by the estimated filtration rate (eGFR). eGFR was calculated using the CKD-EPI equation[18]. Primary patency data were available during the followup. The exclusion criteria were as follows: 1) age $<18$ years; 2) presence of malignant disease, hypotension, active bleeding, or severe liver disease; 3) no known AVF patency at the end of the follow-up period. After excluding relevant indicators, $188 \mathrm{CKD}$ stage 4-5 patients were eligible for inclusion in the study, with a median follow-up time of 41 months.

The study was conducted in accordance with the Declaration of Helsinki, and also under the approval of the Ethics Committee of Qianfoshan Hospital affiliated to Shandong University. The informed consent from patients in the study was waived, however, patients were informed about the registration of all individuals with treated ESRD by the nephrology clinic as well as their right to not participate in the study.

\section{Clinical and laboratory measurements}

Demographic characteristics including age, sex, smoking status and use of prescription drugs, primary renal diseases and comorbidities (hypertension, diabetes and cardiovascular disease) were recorded. Laboratory findings, including hemoglobin, calcium, phosphorus, magnesium, parathyroid hormone (PTH), urea nitrogen, serum creatinine, fasting blood glucose, serum uric acid, serum total cholesterol (TC), and triglycerides (TG), high-density lipoprotein (HDL) cholesterol, and low-density lipoprotein (LDL) cholesterol were measured by the automatic biochemistry analyzer in the central laboratory of Qianfoshan Hospital. Cardiovascular disease (CVD) included ischemic heart disease, heart failure, stroke and peripheral vascular disease was recorded. 


\section{Framingham risk score (FRS)}

FRS were calculated for the total study population based on the following characteristics: age, smoking, diabetes mellitus, systolic blood pressure (mmHg), HDL cholesterol concentration (mg/dL), and TC concentration (mg/dL)[ 14].

\section{Failed AVF}

Failed AVF was defined as the presence of stenosis or thrombosis, and loss of the ability to receive prescribed hemodialysis[13]. Screening was conducted by ultrasonography to assess the degree and location of stenosis or thrombosis and to specify the outflow veins.

\section{Outcomes}

Clinical follow-up was undertaken in the dialysis unit where details of complications with AVF use were recorded. Patients were also contacted by telephone to incorporate a structured interview that included questions on frequency and success at HD, complications (such as stenosis and thrombosis), and any subsequent treatment[ 19]. End points including AVFs failure, all-cause and CVD death.

Sociodemographic characteristics, such as health history (eg, hypertension and diabetes) and lifestyle behavior (eg, smoking and habitual drinking) were obtained by means of questionnaire. The body mass index (BMI) was calculated as weight (in kilograms) divided by height squared (in square meters). Diabetes was defined as fasting blood glucose $\geq$ $7.0 \mathrm{mmol} / \mathrm{L}$ or by the use of hypoglycemic agents or by self-reported history of diabetes. Blood pressure was measured using a sphygmomanometer, and three measurements were taken at $5 \mathrm{~min}$ intervals. The mean of the three readings was calculated, unless the difference between the readings was greater than $10 \mathrm{mmHg}$, in which case the mean of the two closest measurements was used. Hypertension was defined as systolic blood pressure of more than $140 \mathrm{~mm} \mathrm{Hg}$ or diastolic blood pressure of more than $90 \mathrm{~mm} \mathrm{Hg}$, or both, or patients already being priscribed by antihypertensive medicaments. The pulse of waveforms of the right carotid and femoral arteries (cfPWV) was assessed using the SphygmoCor device (AtCor Medical LtD., Sydney, Australia) as previously described[15].

All of the study investigators and staff members completed a training program to learn the methods and procedures of the study.

\section{Statistical analyses}

Data are presented as proportions for categorical variables and mean \pm SD or median [interquartile range (IQR)] for continuous variables. T test or Wilcoxon rank-sum test of variables was used to study the significance of differences in continuous variables between two groups accordingly. Chi-square test was used to study the difference in the distribution of categorical variables. Outcomes of AVF were evaluated using the Kaplan Meier method, and the log-rank test was used to test the differences between different groups. The cumulative primary patency rates were calculated for $12,24,36,48$, and 60 months. Cox proportional hazards models were used to explore the risk factors for AVF failure. Baseline variables including age, sex, smoking status, comorbidities (including hypertension, diabetes and CVD), statins, antiplatelet drugs, calcium, phosphorus, PTH, triglycerides, total cholesterol, HDL, LDL and FRS that were considered clinically relevant were entered into the multivariable regression models. The FRS was analyzed in quartiles. The 25, 50 and 75 percentile of FRS was 12.3, 17.0 and 22.0, respectively. Furthermore, we used the 
Cox proportional hazards analyses to explore the association between the FRS and mortality. Crude and adjusted odds ratios (ORs) with 95\% confidence intervals (CIs) were reported.

All analyses were performed with SPSS statistical package, version 16.0 (SPSS, Inc., Chicago, IL). All p-values are two tailed. A p value $<0.05$ was considered statistically significant.

\section{Results}

\section{Baseline characteristics}

The baseline characteristics of the participants stratified according to the gender were shown in Table 1. The mean age of participants was $57.2 \pm 13.8$ years (range from 20 to 86 years), and $64.9 \%$ of them were males. Diabetic kidney disease (37.8\%) was the major cause of ESRD, and 37.2\% of participants had CVD. Moreover, the FRS was not significantly different between males and females, which was $17.1 \pm 6.2$ and $16.1 \pm 5.6(p=0.29)$, respectively.

\section{Clinical outcomes of AVFs}

During the follow-up period, 45 (23.9\%) patients experienced AVF failure, and the percentage of AVFs failure in females was higher than in males, which was $31.8 \%$ and $19.7 \%$, respectively. In total participants, 11 patients were lost to follow-up, 63 patients died and 114 patients remained alive, Table 1.

In figure 1, the primary patencies of AVFs were $84.6 \%, 79.3 \%, 76.6 \%, 76.1 \%$ and $76.1 \%$ at $12,24,36,48$ and 60 months, respectively. Participants in the lowest quartile of FRS group had better patency rates than in the 2nd Quartile, 3rd Quartile and 4th Quartile of FRS group, which was 91.5\% vs. 85.7\%, 75.0\% and 88.9\% at 12 months, respectively. However, the primary patency decreased to $78.7 \%, 77.6 \%, 66.1 \%$ and $86.1 \%$ in the 1 st Quartile, 2 nd Quartile, 3rd Quartile and 4th Quartile of FRS group at 60 months, respectively. Moreover, there was no significant different in primary patencies among these four groups tested by the log-rank test $(p=0.16)$.

\section{Factors associated with AVF failure}

We confirmed the proportional hazard assumption and conducted Cox proportional hazards regression analyses for risk factors associated with AVF failure. After adjusting for age and sex, age (OR 1.02, 95\% CI, 1.0-1.04) was independent predictors of AVF failure, however, sex, DKD, smoking, hypertension, CVD, statins, antiplatelet drugs, calcium, phosphorus, PTH, TC, TG, HDL, LDL and FRS were not associated with AVF failure (Table 2).

\section{Relationship between FRS and the mortality.}

Furthermore, we used the Cox proportional hazards regression analysis to explore the association between FRS and the mortality. In the crude Cox regression analysis, FRS was independently associated with both all-cause and CVD mortality, with ORs of 1.07 (95\% CI, 1.02 to 1.12) and 1.08 (95\% CI, 1.02 to 1.13), respectively. Moreover, higher quartiles of FRS (Q2, Q3, and Q4 vs. Q1) were independently associated with all-cause mortality, with ORs of 3.29 (95\% CI, 1.31 to 8.23 ), 2.79 (95\% CI, 1.11 to 6.99 ) and 4.77 (95\% CI, 1.90 to 11.94 ), this also independently associated with CVD mortality, with ORs of 3.61 (95\% CI, 1.19 to 10.98), 3.94 (95\% CI, 1.33 to 11.65) and 5.63 (95\% CI, 1.87 to 16.96), respectively. However, these relationships between FRS or different quartiles of FRS with all-cause mortality or 
CVD mortatity disappeared after adjusting for other confounders, including age, gender, diabetic kidney disease, smoking, hypertension, diabetes, CVD, statins, antiplatelet drugs, calcium, phosphorus, parathyroid hormone, triglycerides, total cholesterol, HDL and LDL (Table 3).

\section{Discussion}

Successful establishment of an optimally functioning AVF is a highly desirable result in ESRD patients receiving HD. In fact, there are large international differences exist in successful use of AVF. Successful AVF use was 87\% in Japan, and only 64\% in the United States[10]. In our dialysis unit, AVF placement in distal upper-extremity sites was the first choice for AVF creation when feasible[19]. This cohort study demonstrated that the primary patency of AVFs was $91.5 \%$ and $85.1 \%$ at 12 and 24 months, respectively. Moreover, the failure rate was $21.3 \%$ at 60 months, which further confirms the importance of early detection of clarifying risk factors to prevent AVFs failure.

In the Cox proportional analysis, our study demonstrated that age was positively associated with AVF failure, which probably due to higher vascular stiffness caused by numerous comorbidities, such as hypertension and diabetes. Some of these disease, such as severe arteriopathy are classic predictors of AVF failure[ 16, 17]. Cui et al [20] also found that the primary failure rate was higher for the fistulas compared with the grafts in the elderly patients, which meaned that AVF as first option for HD not necessary in elderly patients. However, a recent multi-center cohort study demonstrated that only post surgery of AVF blood flow and diameter moderately predicted unassisted and overall AVF patency, but, the other factors such as age and sex did not further predict AVF dysfunction[ 12].

There have been studies investigating the molecular mechanisms responsible for AVF failure, such as inflammation and uremia[ 21, 22], which were also the risk factors for CVD. Recent studies demonstrated that the failure of AVF and CVD share several common risk factors, such as elderly, hypertension, diabetes, hyperphosphatemia and arterial stiffness[ 15-17, 23]. FRS is the most commonly used algorithm in clinical practice to predict cardiovascular disease (CVD) risk. Until now, the relationship between FRS and the AVF failure is still uncertain. In our study, participants in the lowest FRS group had better patency rates than in the higher Quartiles of FRS at 12 months. However, there was no 
significant different in primary patencies among these four groups at 60 months tested by the log-rank test. Notably, most of current studies lacking a core outcome of mortality among ESRD patients receiving AVF creation[13]. Moreover, this study did not find FRS associated with mortality among these ESRD patients.

This study also has limitations that deserve attention. First, this is a single-center study, and our prediction models are not calibrated to any other centers, therefore, selection bias in the study limited the extension of the results from this study to other populations. Second, there was a lack of ultrasound findings, such as the presence of vascular calcification and post operative venous dilatation, which might provide important prognostic information. Third, the study sample was relatively small, the negative results could be caused by the limited power.

\section{Conclusion}

In summary, this study did not find FRS associated with AVF failure or mortality among ESRD patients. Currently, there is no widely accepted instrument that comprehensively integrates risk factors associated with AVFs failure. The ideal model should accurately predict future events, be easily implemented, and universally generalize to diverse populations. Therefore, further studies need to be conducted to confirm the importance of clarifying risk factors and implement interventions to prevent the occurrence of AVF failure, improve the lifespan of AVF, and improve the quality of life of patients.

\section{Declarations}

Funding: This study was funded by the Clinical Medicine Innovation Program of the Science and Technology Development Programs from the Ji'nan Science and Technology Bureau (201704086), and the Projects of Medical and Health Technology Development Program of Shandong Province (2017WS083). The funders had no role in study design, data collection and analysis, decision to publish, or preparation of the manuscript.

Authors' contributions

D. J performed the study, researched data, analyzed the results, and wrote the manuscript. C.Q, L.L, and X.D researched data and analyzed the results. K.X conceived the study, analyzed the results and, as such, takes full responsibility for it. All authors have read and approved the manuscript. 
None declared.

Acknowledgements: None.

Availability of data and material

All patient data were stored in the electronic database YIDUCLOUD ( http://192.168.160.2 ). The data set that support the findings is not publicly available because it contains information that could compromise research participant privacy. Limited de-identified data sets may be available from the authors upon reasonable request.

\section{References}

1. Nugent RA, Fathima SF, Feigl AB, Chyung D: The burden of chronic kidney disease on developing nations: a 21st century challenge in global health. Nephron Clinical practice 2011, 118(3):c269-277.

2. Zhang L, Wang F, Wang L, Wang W, Liu B, Liu J, Chen M, He Q, Liao Y, Yu X et al: Prevalence of chronic kidney disease in China: a cross-sectional survey. Lancet 2012, 379(9818):815-822.

3. Chen XN, Pan XX, Yu HJ, Shen PY, Zhang QY, Zhang W, Ren H, Qian Y, Zhu P, Chen N: Analysis of cardiovascular disease in Chinese inpatients with chronic kidney disease. Internal medicine 2011, 50(17):1797-1801.

4. Liyanage T, Ninomiya T, Jha V, Neal B, Patrice HM, Okpechi I, Zhao MH, Lv J, Garg AX, Knight J et al: Worldwide access to treatment for end-stage kidney disease: a systematic review. Lancet 2015, 385(9981):1975-1982.

5. Wang J, Zhang L, Tang SC, Kashihara N, Kim YS, Togtokh A, Yang CW, Zhao MH, North ISN, East Asia Regional B: Disease burden and challenges of chronic kidney disease in North and East Asia. Kidney international 2018, $94(1): 22-25$.

6. Ravani P, Palmer SC, Oliver MJ, Quinn RR, MacRae JM, Tai DJ, Pannu NI, Thomas C, Hemmelgarn BR, Craig JC et al: Associations between hemodialysis access type and clinical outcomes: a systematic review. Journal of the American Society of Nephrology : JASN 2013, 24(3):465-473.

7. Ravani P, Gillespie BW, Quinn RR, MacRae J, Manns B, Mendelssohn D, Tonelli M, Hemmelgarn B, James M, Pannu N et al: Temporal risk profile for infectious and noninfectious complications of hemodialysis access. Journal of the American Society of Nephrology : JASN 2013, 24(10):1668-1677.

8. Sato T, Sakurai H, Okubo K, Kusuta R, Onogi T, Tsuboi M: Current state of dialysis treatment and vascular access management in Japan. The journal of vascular access 2019, 20(1_suppl):10-14.

9. Kim YS, Kim Y, Shin SJ, Lee HS, Kim SG, Cho S, Na KR, Kim JK, Kim SJ, Kim YO et al: Current state of dialysis access management in Korea. The journal of vascular access 2019, 20(1_suppl):15-19.

10. Pisoni RL, Zepel L, Fluck R, Lok CE, Kawanishi H, Suleymanlar G, Wasse H, Tentori F, Zee J, Li Y et al: International Differences in the Location and Use of Arteriovenous Accesses Created for Hemodialysis: Results From the Dialysis Outcomes and Practice Patterns Study (DOPPS). American journal of kidney diseases 2018, 71(4):469-478.

11. Bylsma LC, Gage SM, Reichert H, Dahl SLM, Lawson JH: Arteriovenous Fistulae for Haemodialysis: A Systematic Review and Meta-analysis of Efficacy and Safety Outcomes. European journal of vascular and endovascular 
surgery $2017,54(4): 513-522$.

12. Robbin ML, Greene T, Allon M, Dember LM, Imrey PB, Cheung AK, Himmelfarb J, Huber TS, Kaufman JS, Radeva MK et al: Prediction of Arteriovenous Fistula Clinical Maturation from Postoperative Ultrasound Measurements: Findings from the Hemodialysis Fistula Maturation Study. Journal of the American Society of Nephrology : JASN 2018, $29(11): 2735-2744$

13. Viecelli AK, Tong A, O'Lone E, Ju A, Hanson CS, Sautenet B, Craig JC, Manns B, Howell M, Chemla E et al: Report of the Standardized Outcomes in Nephrology-Hemodialysis (SONG-HD) Consensus Workshop on Establishing a Core Outcome Measure for Hemodialysis Vascular Access. American journal of kidney diseases 2018, 71(5):690-700.

14. D'Agostino RB, Sr., Vasan RS, Pencina MJ, Wolf PA, Cobain M, Massaro JM, Kannel WB: General cardiovascular risk profile for use in primary care: the Framingham Heart Study. Circulation 2008, 117(6):743-753.

15. Hsu YH, Yen YC, Lin YC, Sung LC: Correction: Antiplatelet agents maintain arteriovenous fistula and graft function in patients receiving hemodialysis: A nationwide case-control study. PloS one 2019, 14(4):e0215546.

16. Jankovic A, Damjanovic T, Djuric Z, Marinkovic J, Schlieper G, Tosic-Dragovic J, Djuric P, Popovic J, Floege J, Dimkovic N: Impact of vascular calcifications on arteriovenous fistula survival in hemodialysis patients: a five-year follow-up. Nephron 2015, 129(4):247-252.

17. Choi SJ, Yoon HE, Kim YS, Yoon SA, Yang CW, Kim YS, Park SC, Kim YO: Pre-existing Arterial Micro-Calcification Predicts Primary Unassisted Arteriovenous Fistula Failure in Incident Hemodialysis Patients. Seminars in dialysis 2015, 28(6):665-669.

18. Levey AS, Stevens LA, Schmid CH, Zhang YL, Castro AF, 3rd, Feldman HI, Kusek JW, Eggers P, Van Lente F, Greene T et al: A new equation to estimate glomerular filtration rate. Annals of internal medicine 2009, 150(9):604-612. 19. Zhang Y, Kong X, Tang L, Wei Y, Xu D: Analysis of Follow-Up Methods of Vascular Access and Patient Outcomes in Hemodialysis at a Tertiary Care Hospital in China. Therapeutic apheresis and dialysis 2018, 22(2):160-165.

20. Cui J, Steele D, Wenger J, Kawai T, Liu F, Elias N, Watkins MT, Irani Z: Hemodialysis arteriovenous fistula as first option not necessary in elderly patients. Journal of vascular surgery 2016, 63(5):1326-1332.

21. Stracke S, Konner K, Kostlin I, Friedl R, Jehle PM, Hombach V, Keller F, Waltenberger J: Increased expression of TGF-beta1 and IGF-I in inflammatory stenotic lesions of hemodialysis fistulas. Kidney international 2002, 61(3):10111019.

22. Brahmbhatt A, Remuzzi A, Franzoni M, Misra S: The molecular mechanisms of hemodialysis vascular access failure. Kidney international 2016, 89(2):303-316.

23. Moon JY, Lee HM, Lee SH, Lee TW, Ihm CG, Jo YI, Han SW, Shin SG: Hyperphosphatemia is associated with patency loss of arteriovenous fistula after 1 year of hemodialysis. Kidney research and clinical practice 2015, 34(1):4146.

\section{Tables}


Table 1. Baseline characteristics of participants.

\begin{tabular}{|c|c|c|c|c|}
\hline & Total & Male & Female & P value \\
\hline Number (\%) & 188 & $122(64.9)$ & $66(35.1)$ & \\
\hline Age (years) & $57.2 \pm 13.8$ & $55.0 \pm 13.8$ & $57.3 \pm 14.2$ & 0.27 \\
\hline Cause of kidney disease (n, \%) & & & & 0.02 \\
\hline CGN & $63(33.5 \square$ & $32(26.2 \square$ & $31(47.0 \square$ & \\
\hline $\mathrm{DKD}$ & $71(37.8 \square$ & $51(41.8 \square$ & $20(30.3 \square$ & \\
\hline Others & $54(28.7 \square$ & $39(32.0 \square$ & $15(22.7 \square$ & \\
\hline \multicolumn{5}{|l|}{ Comorbidities (n, \%) } \\
\hline Hypertension & $168(89.4 \square$ & $111(91.0 \square$ & $57(86.4 \square$ & 0.33 \\
\hline Diabetes mellitus & $72(38.3 \square$ & $53(43.4 \square$ & $19(28.8 \square$ & 0.06 \\
\hline $\begin{array}{l}\text { CVD } \\
\text { Current smoking (n, \%) } \\
\text { Medication }(n, \%)\end{array}$ & $\begin{array}{l}70(37.2 \square \\
57(30.3 \square\end{array}$ & $\begin{array}{l}48(39.3 \square \\
55(45.1 \square\end{array}$ & $\begin{array}{l}22(33.3 \square \\
2(3.0 \square\end{array}$ & $\begin{array}{l}0.43 \\
<0.001\end{array}$ \\
\hline Antiplatelet drug $^{\mathrm{a}}$ & $28(14.9)$ & $21(17.2)$ & $7(10.6)$ & 0.29 \\
\hline Statin & $21(11.2)$ & $13(10.7)$ & $8(12.1)$ & 0.81 \\
\hline $\begin{array}{l}\text { SBP (mmHg) } \\
\text { DBP (mmHg) } \\
\text { Hemoglobin }(g / L)\end{array}$ & $\begin{array}{l}158.1 \pm 25.6 \\
89.2 \pm 16.9 \\
90.0 \pm 21.9\end{array}$ & $\begin{array}{l}158.4 \pm 25.6 \\
90.9 \pm 16.7 \\
94.0 \pm 22.7\end{array}$ & $\begin{array}{l}156.0 \pm 26.0 \\
87.8 \pm 15.8 \\
85.3 \pm 20.6\end{array}$ & $\begin{array}{l}0.54 \\
0.22 \\
0.01\end{array}$ \\
\hline Serum albumin $(\mathrm{g} / \mathrm{L})$ & $34.7 \pm 6.4$ & $34.5 \pm 6.6$ & $35.9 \pm 6.8$ & 0.17 \\
\hline Calcium (mmol/L) & $2.06 \pm 0.30$ & $2.03 \pm 0.31$ & $2.09 \pm 0.28$ & 0.19 \\
\hline Phosphorus (mmol/L, IQR) & $1.78(1.45-2.09)$ & $1.80(1.48-2.20)$ & $1.78(1.45-2.09)$ & 0.22 \\
\hline iPTH (pg/ml, IQR) & $185.6(92.2-$ & $200.4(107.6-$ & $192.7(95.4-$ & 0.64 \\
\hline Blood glucose(mmol/L, IQR) & $5.1(4.3-6.3)$ & $5.12(4.39-6.24)$ & $5.11(4.35-6.22)$ & 0.98 \\
\hline Creatinine (mg/dL, IQR) & $7.50(5.27-10.26)$ & $7.89(5.43-10.40)$ & $7.28(5.06-9.56)$ & 0.08 \\
\hline Triglycerides (mmol/L, IQR) & $1.22(0.87-1.78)$ & $1.20(0.82-1.70)$ & $1.22(0.87-1.78)$ & 0.02 \\
\hline $\begin{array}{l}\text { Total cholesterol (mmol/L, } \\
\text { IQR) }\end{array}$ & $\begin{array}{l}4.52 \pm 1.13 \\
1.14 \pm 0.36 \\
2.60 \pm 1.13\end{array}$ & $\begin{array}{l}4.32 \pm 1.17 \\
1.12 \pm 0.40 \\
2.51 \pm 0.80\end{array}$ & $\begin{array}{l}4.83 \pm 1.30 \\
1.15 \pm 0.32 \\
2.71 \pm 0.96\end{array}$ & $\begin{array}{l}0.007 \\
0.62 \\
0.14\end{array}$ \\
\hline Follow-up time (months) & $41.0(29.0-53.0)$ & $41.0(29.0-53.8)$ & $39.0(25.5-52.5)$ & 0.51 \\
\hline FRS & $16.7 \pm 6.0$ & $17.1 \pm 6.2$ & $16.1 \pm 5.6$ & 0.29 \\
\hline AVFs failure (n, \%) & $45(23.9)$ & $24(19.7)$ & $21(31.8)$ & 0.07 \\
\hline All-cause death (n, \%) & $63(35.6)$ & $38(32.8)$ & $25(41.0)$ & 0.32 \\
\hline CVD death $(n, \%)$ & $51(28.8)$ & $33(28.4)$ & $18(27.3)$ & 1.0 \\
\hline
\end{tabular}

Abbreviations: CGN: chronic glomerulonephritis; DKD, diabetic kidney disease; CVD, cardiovascula disease; SBP, systolic blood pressure; DBP, diastolic blood pressure; HDL, high-density lipoprotein; LDI low-density lipoprotein; PTH, parathyroid hormone; FRS, Framingham risk score; AVFs, autologou arteriovenous fistulas.

a Aspirin and/or clopidogrel.

ble 2. Cox proportional hazards analyses for risk factors associated with the failure of AVFs. 


\begin{tabular}{|c|c|c|}
\hline Jariables & Crude OR (95\% CI) & Age- and sex-adjusted OR* (95\% CI) \\
\hline $\operatorname{tge}$ & $1.02(1.0-1.04)$ & $1.02(1.0-1.04)$ \\
\hline Jender (female vs. male) & $1.78(0.99-3.20)$ & $1.74(0.97-3.13)$ \\
\hline KD (yes vs. no) & $1.41(0.78-2.54)$ & $1.35(0.74-2.47)$ \\
\hline jmoking (yes vs. no) & $0.74(0.38-1.46)$ & $0.89(0.42-1.91)$ \\
\hline Aypertension (yes vs. no) & $1.10(0.40-3.08)$ & $1.11(0.39-3.11)$ \\
\hline jVD (yes vs. no) & $1.67(0.93-2.99)$ & $1.52(0.83-2.80)$ \\
\hline jtatins (yes vs. no) & $1.89(0.88-4.06)$ & $1.72(0.79-3.74)$ \\
\hline Intiplatelet drugs (yes vs. no) & $1.71(0.85-3.46)$ & $1.80(0.88-3.69)$ \\
\hline Jalcium (per $1 \mathrm{mmol} / \mathrm{L}$ increase) & $0.81(0.32-2.06)$ & $0.70(0.26-1.89)$ \\
\hline hosphorus (per $1 \mathrm{mmol} / \mathrm{L}$ increase) & $0.74(0.46-1.18)$ & $0.83(0.52-1.33)$ \\
\hline गTH (per $100 \mathrm{pg} / \mathrm{mL}$ increase) & $0.87(0.74-1.03)$ & $0.90(0.77-1.06)$ \\
\hline [riglycerides (per $1 \mathrm{mmol} / \mathrm{L}$ increase) & $0.92(0.63-1.34)$ & $0.84(0.58-1.23)$ \\
\hline [otal cholesterol (per $1 \mathrm{mmol} / \mathrm{L}$ increase) & $1.20(0.95-1.50)$ & $1.11(0.88-1.41)$ \\
\hline HDL cholesterol & $1.49(0.69-3.23)$ & $1.39(0.63-3.06)$ \\
\hline ¿DL cholesterol & $1.33(0.97-1.82)$ & $1.22(0.89-1.66)$ \\
\hline${ }^{7} \mathrm{RS}$ & & $0.97(0.90-1.04)$ \\
\hline${ }^{7} \mathrm{RS}$ (quartiles) & 1. $(0.97-1.07)$ & \\
\hline Quartile 1st & Ref & Ref \\
\hline Quartile 2nd & $1.21(0.51-2.84)$ & $0.88(0.36-2.16)$ \\
\hline Quartile 3rd & $1.93(0.90-4.16)$ & $1.33(0.53-3.36)$ \\
\hline Quartile 4th & $0.79(0.27-2.30)$ & $0.43(0.12-1.52)$ \\
\hline
\end{tabular}

Abbreviation: AVF, autologous arteriovenous fistula; OR, odds ratio; CI, confidence interval; DKD, diabetic kidney disease; CVD, cardiovascular disease; PTH, parathyroid hormone; HDL, high-density lipoprotein; LDL, low-density lipoprotein; FRS, Framingham risk score. The 25, 50 and 75 percentile of framingham risk score was $12.3,17.0$ and 22.0, respectively.

* OR was adjusted for age and sex.

Table 3. Cox proportional hazards analyses for the relationships between FRS and death. 


\begin{tabular}{|c|c|c|c|c|c|}
\hline \multicolumn{3}{|c|}{ All cause death $(\mathrm{n}=63)$} & \multicolumn{3}{|c|}{ CVD death $(\mathrm{n}=51)$} \\
\hline $\begin{array}{l}\text { 'rude } \\
\text { IR } \\
95 \% \\
\text { 'I) }\end{array}$ & $\begin{array}{ll}\text { Age- and } & \text { sex- } \\
\text { adjusted } & \text { OR }^{*} \\
(95 \% \mathrm{CI}) & \end{array}$ & $\begin{array}{l}\text { Multivariable } \\
\text { adjusted OR } \quad \dagger \\
(95 \% \mathrm{CI})\end{array}$ & $\begin{array}{l}\text { Crude } \\
\text { OR } \\
(95 \% \\
\text { CI })\end{array}$ & $\begin{array}{ll}\text { Age- and } & \text { sex- } \\
\text { adjusted } & \text { OR }^{*} \\
(95 \% \mathrm{CI}) & \end{array}$ & $\begin{array}{l}\text { Multivariable } \\
\text { adjusted OR } \quad+ \\
(95 \% \mathrm{CI})\end{array}$ \\
\hline $\begin{array}{l}.07 \\
1.02- \\
.12)\end{array}$ & $1.02(0.96-1.08)$ & $0.96(0.85-1.07)$ & $\begin{array}{l}1.08 \\
(1.02- \\
1.13)\end{array}$ & $\begin{array}{l}1.04(0.97- \\
1.12)\end{array}$ & $1.01(0.88-1.16)$ \\
\hline $\begin{array}{l}\text { lef } \\
.29 \\
1.31- \\
.23) \\
.79 \\
1.11- \\
.99)\end{array}$ & $\begin{array}{l}\text { Ref } \\
2.17(0.82-5.72) \\
1.50(0.52-4.29)\end{array}$ & $\begin{array}{l}\text { Ref } \\
1.83(0.60-5.60) \\
1.32(0.33-5.34)\end{array}$ & $\begin{array}{l}\text { Ref } \\
3.61 \\
(1.19- \\
10.98) \\
3.94 \\
(1.33- \\
11.65)\end{array}$ & $\begin{array}{l}\text { Ref } \\
3.0(0.92-9.79) \\
2.98(0.84- \\
10.50)\end{array}$ & $\begin{array}{l}\text { Ref } \\
3.18(0.76- \\
13.27) \\
3.55(0.61- \\
20.78)\end{array}$ \\
\hline $\begin{array}{l}.77 \\
1.90- \\
1.94) \\
\end{array}$ & $2.20(0.73-6.64)$ & $1.47(0.26-8.22)$ & $\begin{array}{l}5.63 \\
(1.87- \\
16.96) \\
\end{array}$ & $\begin{array}{l}3.97 \\
15.39)\end{array}$ & $\begin{array}{l}4.71 \\
43.94)\end{array}$ \\
\hline
\end{tabular}

Abbreviations: FRS, framingham risk score; OR, odds ratio; CI, confidence interval; CVD, cardiovascula disease.

* OR was adjusted for age and sex.

${ }^{\dagger}$ OR was adjusted for age, gender, diabetic kidney disease, smoking, hypertension, diabetes, CVD, statins, antiplatelet drugs, calcium, phosphorus, parathyroid hormone, triglycerides, total cholesterol, high-density lipoprotein, low-density lipoprotein and FRS.

\section{Figures}




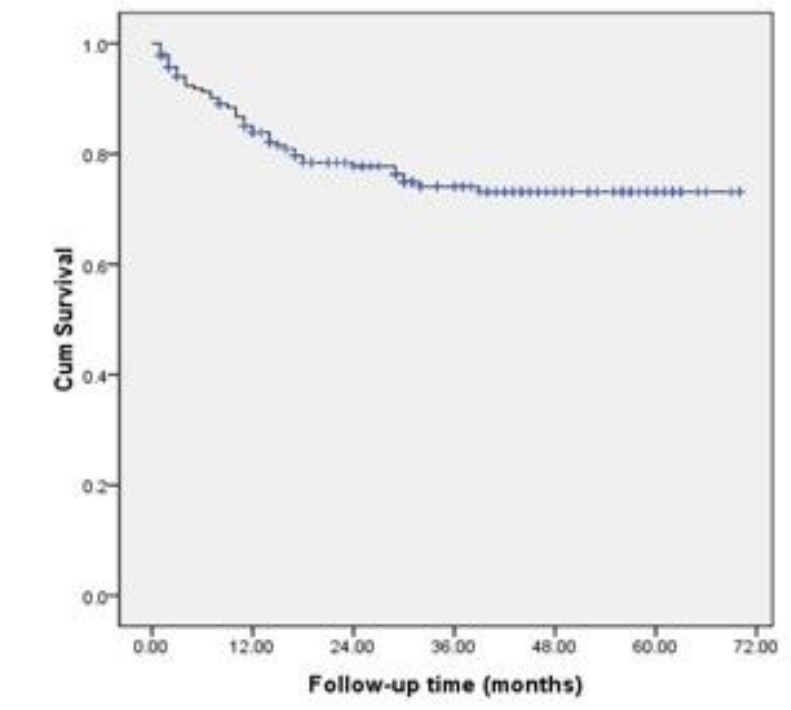

Trots putients
+ Censored

$\begin{array}{lllllll}\text { No. at risk } & 188 & 159 & 149 & 144 & 143 & 143\end{array}$

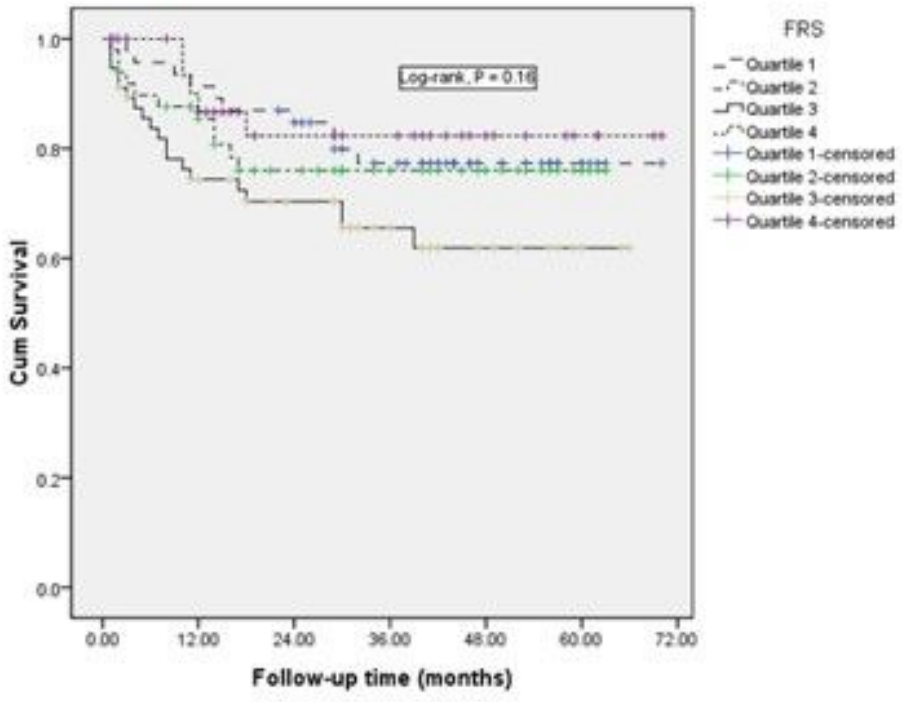

$\begin{array}{lllllll}\text { No. at risk } & & & & & & \\ \text { Quartile 1 } & 47 & 43 & 40 & 37 & 37 & 37 \\ \text { Quartile 2 } & 49 & 42 & 38 & 38 & 38 & 38 \\ \text { Quartile 3 } & 56 & 42 & 40 & 38 & 37 & 37 \\ \text { Quartile 4 } & 36 & 32 & 31 & 31 & 31 & 31\end{array}$

\section{Figure 1}

Kaplan-Meier survival curve analysis of outcomes of the AVFs; A, total patients; B, 4 groups divided by the Framingham risk score (FRS, 1st quartile, 2nd quartile, 3rd quartile, and 4th quartile, log-rank test, $p=$ $0.15)$. 